\title{
Cytokine expression induced by Candida albicans in a model of cutaneous candidosis based on reconstituted human epidermis
}

\author{
MARTIN SCHALLER, REINHARD MAILHAMMER* and HANS. C. KORTING
}

Department of Dermatology and Allergology, University of Munich and * Institute of Clinical Molecular Biology and Tumor Genetics, GSF-National Research Center for Environment and Health, Munich, Germany

\begin{abstract}
Skin equivalents based on reconstituted human epidermis have been used recently to establish models for allergic/irritant contact dermatitis and cutaneous candidosis. In the present study the cytokine expression pattern and the morphological alterations in experimental cutaneous candidosis were investigated by RT-PCR and histological analysis. In experimental cutaneous $C$. albicans infection the mRNA expression levels of interleukin (IL)-1 $\alpha$, IL-1 $\beta$, IL-8, GM-CSF, Exodus-2, tumour necrosis factor- $\alpha$ and PSL (P-selectin ligand) were upregulated. Cytokine profile and histological features of infected skin (separation of keratinocytes, oedema, vacuolisation) were comparable to that seen in experimental contact dermatitis. These immunomodulatory and morphological similarities might reflect a common pathogenesis factor in both diseases.
\end{abstract}

\section{Introduction}

The local immune reponse of the host cells seems to be an important factor in mucocutaneous infection by Candida albicans. Studies with mice have demonstrated increased expression of chemokines and a Th1type cell-mediated immunity in experimental oral [1] and vaginal candidosis [2-7]. Host defence mechanisms are poorly understood in cutaneous candidosis [8]. An earlier study established a three-dimensional model of cutaneous candidosis based on reconstituted human epidermis and demonstrated that secreted aspartyl proteinases are important virulence factors for infection [9]. In the present study the local production of cytokines during experimental cutaneous infection with C. albicans by RT-PCR was investigated.

\section{Materials and methods}

Candida strain and growth conditions

The clinical isolate C. albicans SC5314 was used for

Received 3 Dec. 2001; revised version accepted 18 Feb. 2002.

Corresponding author: Dr M. Schaller (e-mail: Martin. Schaller@lrz.uni-muenchen.de). the infection of the reconstituted epidermis [10]. Inocula were prepared as described previously [9].

\section{Model of cutaneous candidosis}

The reconstituted human epidermis for the in-vitro model of cutaneous candidosis was supplied by Skinethic $^{\mathrm{TM}}$ Laboratory (Nice, France). It consists of a three-dimensional keratinocyte multilayer without any other cell type. All media for cell culture were prepared without antibiotics and antimycotic agents. The epidermal samples were infected with $2 \times 10^{6}$ Candida yeast cells in $100 \mu \mathrm{l}$ of phosphate-buffered saline (PBS) as described previously. Controls contained $100 \mu \mathrm{l}$ of PBS alone. In all experiments infected and uninfected cultures were incubated at $37^{\circ} \mathrm{C}$ with $\mathrm{CO}_{2} 5 \%$ at $100 \%$ humidity for 24 and $48 \mathrm{~h}$.

\section{Light microscopy}

Light microscopical studies were performed as described previously to evaluate histological changes during infection [9]. Semi-thin sections $(1 \mu \mathrm{m})$ were stained with toluidine blue $1 \%$ and pyronin G (Merck, Darmstadt, Germany) $1 \%$. The histological changes in the epidermis were evaluated on the basis of 50 sections from 5 different sites for each infected epithelium. 


\section{$R N A$ analysis and reverse transcription}

Reconstituted epithelia were lysed for $30 \mathrm{~s}$ in $1 \mathrm{ml}$ of lysis buffer (RNeasy kit, QIAGEN, Hilden, Germany) with a mechanical blender (Ultraturrax, IKA, Karlsruhe, Germany). During RNA purification, genomic DNA was digested with RNAase-free DNAase (QIAGEN). Reverse transcription of total RNA was performed at $1 \mu \mathrm{g}$ total RNA in $10 \mu \mathrm{l}$ final volume for $55 \mathrm{~min}$ at $37^{\circ} \mathrm{C}$ with $100 \mathrm{U}$ of Moloney murine leukaemia virus reverse transcriptase (Life Technologies $\mathrm{GmbH}$, Eggenstein, Germany) in the presence of $1 \mathrm{mM}$ each deoxynucleoside triphosphate (dNTP) (Amersham Biosciences, Freiburg, Germany), recombinant ribonuclease inhibitor (Promega, Madison, WI, USA) $10 \mathrm{U}, 15 \mathrm{mM}$ Tris-Cl (pH 8.4), $60 \mathrm{~mm} \mathrm{KCl,} 3 \mathrm{mM}$ $\mathrm{MgCl}_{2}$, Tween $200.3 \%$, oligo $(\mathrm{dT})_{15} 0.1 \mu \mathrm{g}$ and $10 \mathrm{mM}$ $\beta$-mercaptoethanol. After incubation for $5 \mathrm{~min}$ at $95^{\circ} \mathrm{C}$ the cDNA was finally diluted to $10 \mathrm{ng} / \mu \mathrm{l}$ with water and stored at $-80^{\circ} \mathrm{C}$.

\section{RT-PCR}

In a final volume of $20 \mu \mathrm{l}$ (with oil overlay) PCR samples contained dimethyl sulphoxide 5\%, $60 \mathrm{mM}$ $\mathrm{KCl}, 10 \mathrm{~mm}$ Tris-Cl (pH 8.4), $1.6 \mathrm{mM} \mathrm{MgCl}_{2}$, Tween $200.3 \%, 0.2 \mathrm{mM}$ of each dNTP, 10 pmol of each primer, Taq DNA polymerase (Promega) $0.6 \mathrm{U}$ and $20 \mathrm{ng}$ of cDNA. Thirty cycles of $1 \mathrm{~min}$ at $95^{\circ} \mathrm{C}, 1 \mathrm{~min}$ at $65^{\circ} \mathrm{C}, 1 \mathrm{~min}$ at $72^{\circ} \mathrm{C}(5 \mathrm{~min}$ final $)$ were performed. PCR-amplified products were visualised by agarose gel electrophoresis of $10-\mu 1$ samples and ethidium bromide staining. A 100-bp ladder (Amersham Pharmacia Biotech, Freiburg, Germany) was used as a DNA mol. wt marker.

The following human primers were used (the sequences are given in the $5^{\prime}$ to $3^{\prime}$ direction):

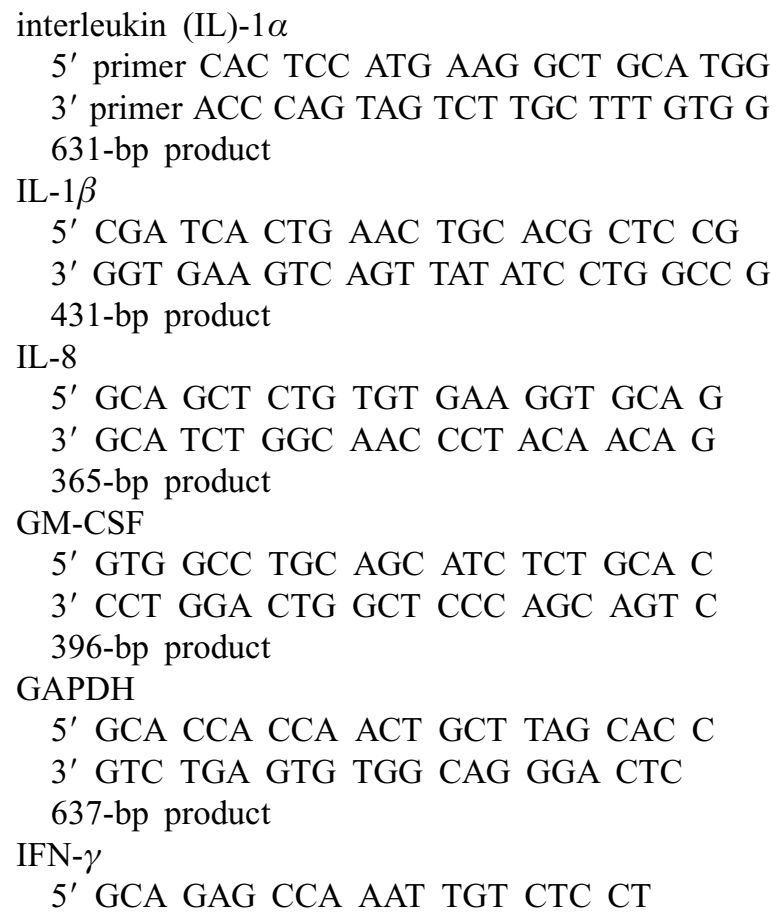

\author{
$3^{\prime}$ ATG CTC TTC GAC CTC GAA AC \\ 290-bp product \\ TNF- $\alpha$ \\ 5' GGG ACC TCT CTC TAA TCA GCC CTC \\ TGG \\ 3' GACGGCGATGCGGCTGATGG \\ 287-bp product \\ Exodus-2 \\ 5' CAA GCG CTC TCA GGC AGA GC \\ 3' TCT GGA CCT GGC CTG CTG \\ 420-bp product \\ TGF- $\alpha$ \\ 5' CAG ATC CTG TCC AAG CTG CGG C \\ 3' GAA TGG TGG CCA GGT CAC CTC GGC \\ 600-bp product \\ PSL
5' CTT CTT CGT GTG CAC TGT GGT G
3' GAT GGC AGA GTG AGC TAA GGG \\ 255-bp product
}

GAPDH primers were used as a positive internal mRNA control. To verify the absence of genomic DNA, the designed primers amplified across an intron. The expected size of the amplicons proved that only cDNA was amplified.

\section{Results}

Epidermal morphology after infection with

C. albicans

C. albicans infection of the reconstituted human epidermis confirmed the previously described morphological alterations, i.e., oedema, vacuolisation and detachment of cells (Fig. 1).

\section{Basal cytokine expression of uninfected epidermis}

Expression of cytokines was monitored 0, 24 and $48 \mathrm{~h}$ after incubation with PBS. The housekeeping gene GAPDH served as a positive control for RT-PCR reaction and demonstrated equal amounts of cDNA in the different samples. RT-PCR analysis demonstrated

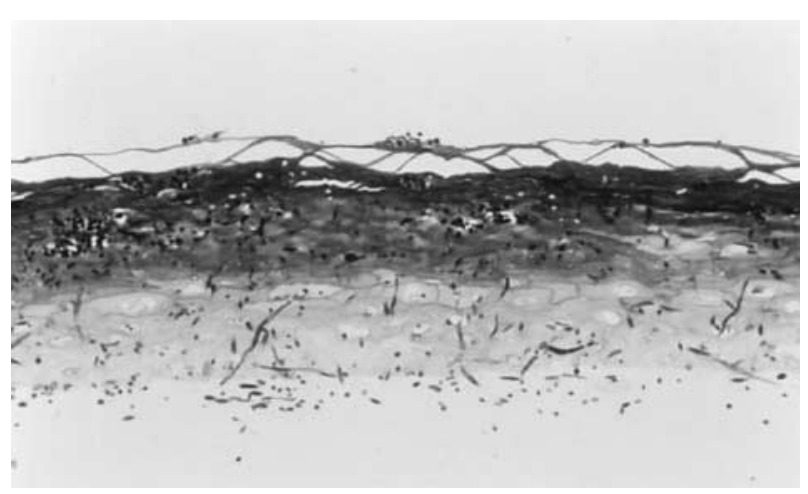

Fig. 1. Model of cutaneous candidosis based on reconstituted human epidermis. C. albicans-induced morphological alterations $24 \mathrm{~h}$ after infection include separation and detachment of cell layers, oedema and vacuolisation. 
constant mRNA expression levels for GAPDH, IL-1 $\alpha$, IL- $1 \beta$, IFN- $\gamma$, Exodus-2, TGF- $\beta$, TNF- $\alpha$ and PSL in all uninfected epidermal samples at the indicated time points (shown for $48 \mathrm{~h}$ PBS in Fig. 2). No signals were seen for G-CSF, GM-CSF, M-CSF, hsp-70, the cytokines IL-2, IL-3, IL-4, IL-5, IL-6, IL-7, IL-8, IL-9, IL-10, IL-11, IL-13, IL-14, IL-15, IL-16, IL-17 and the chemokines BCA-1, HCC-1, I-309, I-TAC, IP10, MCP-1, MIG, MIP-1 $\alpha, \quad$ MIP-1 $\beta, \quad$ MIP-3 $\beta$, RANTES, SDF- $1 \beta$ and TARC (Fig. 2 and data not shown).

\section{Regulation of cytokine mRNA expression during epidermal infections with $C$. albicans}

Regulation of cytokine mRNA expression during infection of reconstituted epidermal samples (over 24 and $48 \mathrm{~h}$ ) with $C$. albicans induced new expression of IL-8 and GM-CSF. During the course of infection, the amounts of mRNA coding for IL- $1 \alpha$, IL- $1 \beta$, Exodus-2, TNF- $\alpha$ and PSL were upregulated while the levels of
GAPDH and IFN- $\gamma$ mRNA remained constant. Expression signals for TGF- $\beta$ were upregulated after $24 \mathrm{~h}$ but not detectable $48 \mathrm{~h}$ after infection (Fig. 2).

\section{Discussion}

Models of superficial candidosis based on reconstituted epidermis have been used successfully to investigate virulence factors of $C$. albicans, such as the gene family of secreted aspartyl proteinases [9]. The present investigation demonstrated that uninfected reconstituted human epidermis is able to express a cytokine profile which is very similar to that observed in vivo or in other in-vitro studies [11-13]. Moreover, it demonstrated a basal expression of PSL and Exodus-2 by keratinocytes which has not been reported before. Expression of Exodus-2 was demonstrated in lymph node tissue and in monocytes and is important for the adhesion and migration of human $\mathrm{T}$ cells [14]. PSL(P-selectin ligand) expression by endothelial cells and

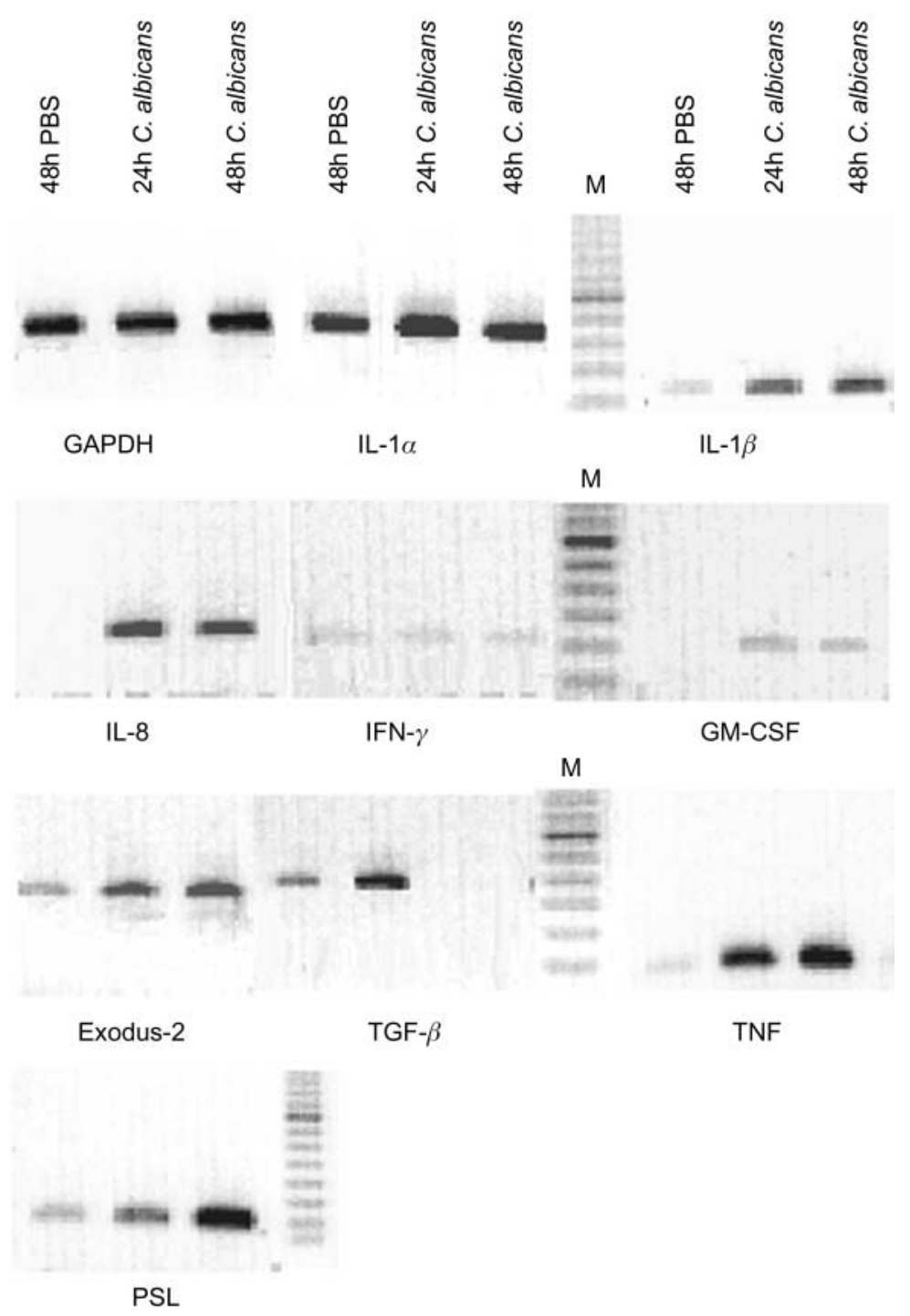

Fig. 2. Kinetics of cytokine expressions in uninfected reconstituted human epidermis ( $48 \mathrm{~h}$ PBS) and 24 and $48 \mathrm{~h}$ after stimulation with $C$. albicans. GAPDH was used as an internal mRNA control. M, 100-bp mol. wt marker. 
platelets is important for leucocyte migration [15]. To investigate if the expression of Exodus-2 and PSL by epidermal keratinocytes may also play a significant role in host inflammatory response, the regulation of these genes after infection with $C$. albicans was studied. Infection of reconstituted human epidermis with $C$. albicans increased the expression levels of IL1- $\alpha$, IL- $1 \beta$, Exodus-2, TNF- $\alpha$ and PSL, while the amount of TGF- $\beta$ transcripts was decreased. As expected, relatively constant mRNA expression levels during infection were seen for the housekeeping gene GAPDH, proving equivalence of the skin culture samples used. IFN- $\gamma$ mRNA levels were also equal. Expression of the pro-inflammatory cytokines IL-8 and GM-CSF, which are chemotactic for monocytes, lymphocytes and neutrophils [11], was induced de novo by infection with $C$. albicans. The great influence of these cells in the in-vivo defence against invading fungal pathogens confirms the relevance of this candidosis model to pathogenesis. Both chemotactic mediators IL-8 and GM-CSF are especially important for the recruitment of neutrophils [11], which are frequently seen in cutaneous candidosis in vivo. Increased transcription levels of IL $1-\alpha$, IL- $1 \beta$, TNF- $\alpha$, Exodus- 2 and PSL stimulated by experimental $C$. albicans infection are linked in vivo with a protective Th1-type cytokine response or with chemotaxis and activation of macrophages, neutrophils and lymphocytes $[11,12,16]$. Recently, it was demonstrated that local production of TGF- $\beta$ contributes to disease progression in $C$. albicans infection [6]. Down-regulation of the Th2-type cytokine TGF- $\beta$ in the model used in the present study supports the induction of a protective Th1 response. Induction of a protective Th1-type cytokine response by $C$. albicans was demonstrated previously in several murine models for systemic or mucosal infections $[1,2,16]$. This study presents evidence that chemotaxis and the Th1-type of cytokine response are induced in the earliest stage of contact with the pathogen and without the influence of other immunocompetent cells. Recently, skin equivalents were also used to investigate the cytokine profiles triggered by allergic and sensitising agents [17-21]. A critical review of the results of studies dealing with this topic showed that a clear discrimination between an allergic or a toxic immune response by analysis of the cytokine mRNA expression is difficult. Cytokine expression patterns observed in reconstituted human epidermis after treatment with allergic or toxic agents, or both, are similar to those seen after infection with $C$. albicans. In previous studies, the skin reactions seen in experimental C. albicans infection have been explained as a sort of biological contact dermatitis of the primary irritant or allergic type [22-25]. The present study found morphological alterations and a cytokine profile of reconstituted human epidermis induced by $C$. albicans infection, which are similar to that found in irritant/ allergic contact dermatitis [18]. This might suggest an irritant/allergic effect of C. albicans in the pathogenesis of cutaneous candidosis.
The work was supported by a grant from the Deutsche Forschungsgemeinschaft DFG, awarded to H.C.K., R.M. and M.S. (KO 1106/ 4-1).

\section{References}

1. Elahi S, Pang G, Clany R, Ashman RB. Cellular and cytokine correlates of mucosal protection in murine model of oral candidiasis. Infect Immun 2000; 68: 5771-5777.

2. De Bernardis F, Santoni G, Boccanera $\mathrm{M}$ et al. Local anticandidal immune responses in a rat model of vaginal infection by and protection against Candida albicans. Infect Immun 2000; 68: 3297-3304.

3. Fidel PL, Lynch ME, Sobel JD. Candida-specific cell-mediated immunity is demonstrable in mice with experimental vaginal candidiasis. Infect Immun 1993; 61: 1990-1995.

4. Fidel PL, Lynch ME, Sobel JD. Candida-specific Th1-type responsiveness in mice with experimental vaginal candidiasis. Infect Immun 1993; 61: 4202-4207.

5. Saavedra M, Taylor B, Lukacs N, Fidel PL. Local production of chemokines during experimental vaginal candidiasis. Infect Immun 1999; 67: 5820-5826.

6. Taylor BN, Saavedra M, Fidel PL. Local Th1/Th2 cytokine production during experimental vaginal candidiasis: potential importance of transforming growth factor-beta. Med Mycol 2000; 38: 419-431.

7. Wormley FL, Chaiban J, Fidel PL. Cell adhesion molecule and lymphocyte activation marker expression during experimental vaginal candidiasis. Infect Immun 2001; 69: 5072-5079.

8. Murphy JW, Bistoni F, Deepe GS et al. Type 1 and type 2 cytokines: from basic science to fungal infections. Med Mycol 1998; 36 (Suppl 1): 109-118.

9. Schaller M, Schackert C, Korting HC, Januschke E, Hube B. Invasion of Candida albicans correlates with expression of secreted aspartic proteinases during experimental infection of human epidermis. J Invest Dermatol 2000; 114: 712-717.

10. Gillum AM, Tsay EYH, Kirsch DR. Isolation of the Candida albicans gene for orotidine-5'-phosphate decarboxylase by complementation of $S$. cerevisiae ura3 and $E$. coli pyrF mutations. Mol Gen Genet 1984; 198: 179-182.

11. Stadnyk A. Cytokine production by epithelial cells. FASEB $J$ 1994; 8: 1041-1047.

12. Ansel J, Perry P, Brown $\mathrm{J}$ et al. Cytokine modulation of keratinocyte cytokines. J Invest Dermatol 1990; 94 (6 Suppl): $101 \mathrm{~S}-107 \mathrm{~S}$.

13. Ogawa H, Summerbell RC, Clemons KV et al. Dermatophytes and host defence in cutaneous mycoses. Med Mycol 1998; 36 (Suppl 1): 166-173.

14. Robertson MJ, Williams BT, Christopherson K, Brahmi Z, Hromas R. Regulation of human natural killer cell migration and proliferation by the exodus subfamily of CC chemokines. Cell Immunol 2000; 199: 8-14.

15. Vestweber D, Blanks JE. Mechanisms that regulate the function of the selectins and their ligands. Physiol Rev 1999; 79: $181-213$.

16. Romani L. Innate and adaptive immunity in Candida albicans infections and saprophytism. J Leukoc Biol 2000; 68: 175-179.

17. Coquette A, Berna N, Poumay Y, Pittelkow MR. The keratinocyte in cutaneous irritation and sensitization. In: Kydonieus AF, Willie JJ (eds) Biochemical modulation of skin reactions: transdermals, topicals, cosmetics. Boca Raton, FL, CRC Press. 2000: 125-138.

18. Coquette A, Berna N, Vandenbosch A, Rosdy M, Poumay Y. Differential expression and release of cytokines by an in vitro reconstructed human epidermis following exposure to skin irritant and sensitizing chemicals. Toxicol Vitro 1999; 13: $867-877$

19. Burleson FG, Limardi LC, Sikorski EE, Rheins LA, Donnelly TA, Gerberick GF. Cytokine mRNA expression in an in vitro human skin model, SKIN2 ${ }^{\mathrm{TM}}$. Toxicol Vitro 1996; 10: 513-521.

20. Sikorski EE, Gerberick GF, Limardi LC. Evaluation of a human skin equivalent model as an in vitro system to evaluate the contact sensitization potential of chemicals. $J$ Invest Dermatol 1996; 106: 939.

21. Sikorski EE, Gerberick GF, Limardi LC. Evaluation of cytokine message levels in the Epiderm TM in vitro skin model following application of contact allergens and skin irritants. J Invest Dermatol 1997; 108: 662. 
22. Maibach HI, Kligman AM. The biology of experimental human cutaneous moniliasis (C. albicans). Arch Dermatol 1962; 85: 233-257.

23. Rebora A, Marples RR, Kligman AM. Experimental infection with Candida albicans. Arch Dermatol 1973; 108: 69-73.

24. Marples RR, Rebora A, Kligman AM. Topical steroid- antibiotic combinations. Assay of use in experimentally induced human infections. Arch Dermatol 1973; 108: $237-240$.

25. Tagami H, Urano-Suehisa S, Hatchome N. Contact sensitivity to Candida albicans - comparative studies in man and animal (guinea-pig). $\mathrm{Br} J$ Dermatol 1985; 113: 415-424. 